\title{
Biochemical studies on the effect of Crataegus aqueous extract on oxidative stress during ischemia/reperfusion induced myocardial injuries
}

\author{
Mustafa T. Mohammed*
}

\author{
Bsc, Msc, PhD (Biochemistry)
}

Abstract:

J Fac Med Baghdad 2015; Vol.57, No.3 Received Mar. 2015 Accepted Apr.2015

Background: myocardial ischemia-reperfusion (I/R) injury may occur in a variety of clinical settings and this remains a significant problem. Oxygen free radicals, produced on reperfusion have been shown to play a major role in myocardial I/R injury. Various therapeutic effects have been described for Crataegus. Additionally, it has been presented that Crataegus has protective effect against ischemia reperfusion induced myocardial injuries to various organs. Therefore, it seems possible that the administration of Crataegus might protect the heart against the ischemia reperfusion injury.

Objectives: I detected the chemical components and trace elements of the aqueous extract of Crataegus leaves and determine whether Crataegus extract prevents or decreases ischemia-reperfusion induced myocardial injuries in rats.

Methods: The chemical composition of the aqueous extracts of the Crataegus leaves was analysed and concentration of some trace elements was estimated.Thirty-six rats were divided into three groups as control, $\mathrm{I} / \mathrm{R}$ group and Crataegus treatment group. Blood samples were taken from the rats for the biochemical parameters estimating, serum aspartate aminotransferase (AST), alanine aminotransferase (ALT), lactate dehydrogenase (LDH) oxidative stress levels of nitric oxide (NO) and lipid peroxidation (LPO).

Results: The results showed that the extract contain: glycosides saponins, tannins ,phenolic compounds , proteins and flavonoids. The results also showed that there were high concentrations of $\mathrm{K}, \mathrm{Na}, \mathrm{Ca}$ with $(171.2,19,18.3)$ ppm, respectively and low concentrations of $\mathrm{Fe}, \mathrm{Zn}, \mathrm{Cu}, \mathrm{Mg}$ with $(5.1,3.2,2.3$,1.9) ppm, respectively, very low concentrations $\mathrm{Cr}, \mathrm{Cd}, \mathrm{Pb}$ with $(0.9,0.7, \mathrm{Nil}) \mathrm{ppm}$. The levels of heart enzymes and Oxidative stress in group 3 were significantly lower than those in the group 2.Our results suggest that Crataegus treatment protects the rat heart against ischemia-reperfusion induced myocardial injuries.

Conclusion: The present study confirms that the aqueous extract of Crataegus contains (glycosides, tannins, proteins, saponins, phenolic compounds and flavonoids) as well as our results suggest that Crataegus treatment protects the rat heart against ischemia-reperfusion induced myocardial injuries .

Key words: Crataegus, ischemia/reperfusion, myocardial injuries.

Introduction:

Ischemic heart diseases remain the leading cause of death in most developing countries as seen over the past quartercentury. Oxidative stress defines that, the level of Reactive Oxygen Species (ROS) exists in excess of antioxidant defenses. This inequity in the redox milieu results in a switch from ROS-stimulated ambient signaling processes to ROSmediated pathophysiological consequences. Oxidative stress has been implicated in the installation and progression of several degenerative diseases via DNA mutation, protein oxidation and/or lipid peroxidation. In the vasculature, oxidant stress may result from either over production of ROS and/or a decrease in antioxidant capacity when either predominates in the vessel wall, the net result is ROS-mediated decrease in bioavailable nitric oxide and oxidative modification of lipids and proteins leading to impaired vasomotor reactivity, inflammation and dysregulated cell proliferation [1]. Cardiac

*Dept. of Chemistry, College of Science, Al-Mustansiriyah University, Baghdad, Iraq.

Email:Tahabiochem@yahoo.comto ischemia is a condition in which blood flow and oxygen supply are insufficient the heart muscle. The main cause of cardiac ischemia is narrowed coronary arteries. When arteries are narrowed, there is less blood and oxygen supply to the heart muscles. Cardiac ischemia leads to coronary heart disease, angina pectoris, myocardial infarction, heart failure and ultimately heart attack [2]. Medicinal plants have been traditionally used in the treatment of several human diseases and their pharmacological and therapeutic properties have been attributed to different chemical constituents isolated from their crude extracts. Particularly the chemical constituent of antioxidant activity can be found at high concentration in plants and can be responsible for their preventing effects in various degenerative diseases, including, neurological and cardiovascular diseases as well as in cacer. Thus, the antioxidant properties of plants have full range of perspective applications in human health care [3]. Crataegus (Hawthorn) is one of the oldest medicinal plants and is described by many pharmacopoeias. Crataegus extract from leaves with flowers 
has been used to treat the early stages of congestive heart failure and angina pectoris[4]. Pharmacological studies also demonstrate that Hawthorn extract from fruit and flowerscan decrease the level of cholesterol in serum[5] and inhibit platelet conglomeration[6] .Evidences show that Crataegus extract from several parts of the plant including leaves has antioxidant effects in vitro or in vivo, Crataegus extract scavenges superoxide anion,hydroxyl radical, and hydrogen peroxides, and inhibits lipid peroxidation[7-8].In vivo experiments show that Crataegus extract from fruit increases the concentration of a-tocopherol and inhibits the oxidation of human lowdensity lipoprotein (LDL) [9]. Clinical studies indicate that its antioxidant activity is the mechanism of Hawthorn extraction's cardioprotective benefit[10].

\section{Materials and Methods:}

Leaves of Crataegus were collected from an area north of Baghdad, Iraq. Leaves were washed, cleaned with filter paper or soft clothes to remove all traces of dust and insects, then dried in shade $25-30^{\circ} \mathrm{C}$ for one week, with continuous overturn to prevent mould,weighed, ground in a mortar and pestle, placed in airtight bottles and stored in dissicator to be used for extraction . $50 \mathrm{~g}$ Air dried leaves were suspended in one liter of distilled water and left for $24 \mathrm{hrs}$ at $35^{\circ} \mathrm{C}$ with continuous stirring in a shaking incubator.Then the mixture was filtered by filter paper № 42 , the filtrate was centrifuged for $10 \mathrm{~min}$. at $2500 \mathrm{rpm}$, and the extract evaporated to dryness at $40^{\circ} \mathrm{C}$ in the incubator. The chemical components of the prepared watery extract were detected as shown in table .1.and the trace elements were determined [11] Experimental Design:Thirty-six male Wistar rats weighting 200-230g were used in this experimental study. All animals were maintained under standard conditions. Rats were deprived of food, but not water, for $24 \mathrm{~h}$ before surgery (ischemia and reperfusion). Animals were divided into three groups fed for 15 days with the same diet:, sham group (Group 1), I/R group (Group 2), and Crataegus (aqueous extract )treatment group (Group 3). All rats were anesthetized with $40-50 \mathrm{mg} / \mathrm{kg}$ of thiopental sodium. Crataegus was given to the rats in treatment group, before ischemia and before reperfusion at a dose of $1 \mathrm{~mL} / \mathrm{kg}$ by intraperitoneal route. Surgical procedure: The ischemiareperfusion injury was produced in rat heart based on Buerke's description with modifications [12-13] . Rats were placed on a warm board to control the body temperature at $37{ }^{\circ} \mathrm{C}$ for surgery. The chest was opened at the left fourth intercostal space. The pericardium was incised and the left atrium appendage was elevated to expose the left anterior descending (LAD) coronary artery. A 6-0 silk suture was passed around the LAD coronary artery, and the ends of suture were threaded through a small vinyl tube to form a snare. The thoracic cavity was covered with saline-soaked gauze to prevent the heart from drying. , ischemia was established by tightening the suture from both ends with fixed weight. The animals then underwent 45 min of ischemia, . Reperfusion was introduced by releasing the snare gently for a period of $60 \mathrm{~min}$. The sham control animals were subjected to the entire surgical procedure described above, except the introduction of LAD ligation and release. At the end of reperfusion, the estimation of the biochemical parameters.

a)Heart enzymes : Plasma was used to measure AST, ALT and $\mathrm{LDH}$ as indicative parameters of heart function. The plasma activities of AST, ALT and LDH were estimated by commercially available kits using an autoanalyser (aeroset ${ }^{\circledR}$ Abbott Laboratories, Chicago, IL ).

b)Oxidative stress indices: The left hemisphere was used to detect nitric oxide (NO) measured as total nitrite[14] and lipid peroxidation (LPO) as Thio Barbituric Acid Reactive Substances [15]. At the end of the experiment, heart tissue was immediately fixed in $10 \%$ buffered neutral formalin solution. The fixed tissues were embedded in paraffin and serial sections were cut. The sections were examined under light microscope after hematoxylin and eosin staining and photomicrograph.

\section{Results:}

The qualitative chemical analyses of the aqueous extracts are illustarted in Table.1,which indicate that leaves contents are glycosides, proteins, saponins, tannins and phenolic compounds and flavonoids. The obtained results were in agreement with preivious studies[16].

Table 1: Phytochemical Composition for aqueous extract of Crataegus leaves.

\begin{tabular}{|c|c|c|c|}
\hline Phytochemical & Reagents & Note & $\begin{array}{c}\text { Result } \\
\text { Watery extract }\end{array}$ \\
\hline Glycosides & $\begin{array}{l}\text { Iodine test } \\
\text { Molish test } \\
\text { Benedict test }\end{array}$ & $\begin{array}{l}\text { Blue ppt. } \\
\text { Violet ring } \\
\text { Orange ppt. }\end{array}$ & $\begin{array}{l}\mathrm{Ve}+ \\
\mathrm{Ve}+ \\
\mathrm{Ve}+\end{array}$ \\
\hline Proteins & $\begin{array}{c}\text { Folin-Ciocalteau } \\
\text { reagent }\end{array}$ & Blue color & $\mathrm{Ve}+$ \\
\hline Saponins & $\begin{array}{l}\text { Fast stirring } \\
\text { Mercuric } \\
\text { Chloride }\end{array}$ & $\begin{array}{l}\text { Dense foam } \\
\text { for long time } \\
\text { White ppt. }\end{array}$ & $\begin{array}{l}\mathrm{Ve}+ \\
\mathrm{Ve}+\end{array}$ \\
\hline $\begin{array}{l}\text { Phenolic } \\
\text { compounds }\end{array}$ & $\begin{array}{c}\text { Aqueous1\% } \\
\text { Ferric chloride }\end{array}$ & Green ppt. & $\mathrm{Ve}+$ \\
\hline Tannins & $\begin{array}{c}\text { Aqueous1\% } \\
\text { Ferric chloride } \\
\text { Lead acetate1\% }\end{array}$ & $\begin{array}{l}\text { Green ppt. } \\
\text { Preface } \\
\text { yellow ppt. }\end{array}$ & $\begin{array}{l}\mathrm{Ve}+ \\
\mathrm{Ve}+\end{array}$ \\
\hline Flavonoids & $\begin{array}{c}\text { aqueous1\% } \\
\text { Ferric chloride } \\
\text { Ethanol } \\
\text { hydroxide } \\
\text { alcohol }\end{array}$ & $\begin{array}{l}\text { Green ppt. } \\
\text { Yellow ppt. }\end{array}$ & $\begin{array}{l}\mathrm{Ve}+ \\
\mathrm{Ve}+\end{array}$ \\
\hline
\end{tabular}

Key: $+++=$ Presence of bioactive compound in very high concentration

$++=$ High concentration

$+=$ Presence of bioactive compound

Figure 1 shows the concentrations of trace elements in Crataegus leaves. The results reveals the presence of a high concentrations of $\mathrm{K}, \mathrm{Na}$ and $\mathrm{Ca}$ with $171.2,19,18.3 \mathrm{ppm}$, respectively and low content of $\mathrm{Fe}, \mathrm{Zn}, \mathrm{Cu}$ and $\mathrm{Mg}$ with $5.1,3.2,2.3$ and 1.9 ppm, respectively . ther is very low concentrations of $\mathrm{Cr}$ and $\mathrm{Cd}$. 


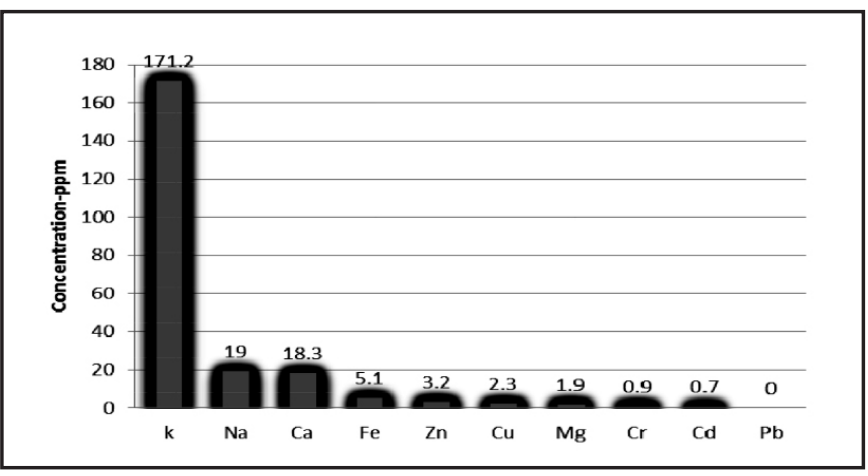

Figure 1: heavy metal content of Crataegus leaves.

As anticipated, I/R caused production of oxygen free radicals has been clarified in ischemic reperfused heart, leading to tissue damage as indicated by increased levels of ALT, AST, and LDH (in the I/R group) while ALT, AST, and LDH levels in the Crataegus treatment group were significantly lower than those in the I/R group (they were significantly higher in the I/R group than those in the control group). The results are depicted in Table 2.

Table 2. Clinical parameters in control, $I / R$ and $I / R+$ Crataegus, rats $(n=12$, mean \pm SD)

\begin{tabular}{ccccc}
\hline $\begin{array}{c}\text { Clinical } \\
\text { parameters }\end{array}$ & control & I/R & $\begin{array}{c}\text { I/R }+ \\
\text { Crataegus }\end{array}$ & P \\
\hline AST (U/L) & $\mathbf{1 3 4} \pm 18$ & $\mathbf{9 9 5} \pm \mathbf{1 8 6}$ & $\mathbf{5 6 7} \pm 89$ & $\mathbf{0 . 0 0 1}$ \\
\hline ALT (U/L) & $\mathbf{8 4} \pm 14$ & $\mathbf{8 6 4} \pm \mathbf{2 0 8}$ & $\mathbf{5 7 4} \pm 137$ & $\mathbf{0 . 0 0 1}$ \\
\hline LDH (U/L) & $\mathbf{5 2 4} \pm 172$ & $\mathbf{2 8 5 4} \pm 426$ & $\mathbf{2 4 6 1} \pm 498$ & $\mathbf{0 . 0 0 1}$ \\
\hline
\end{tabular}

AST: Aspartate aminotransferase; ALT: Alanine aminotransferase; LDH: Lactate dehydrogenase

Significances against controls: $* \mathrm{P}<0.001$

Table 3 shows increased oxidative stress levels of NO and LPO while oxidative stress $\mathrm{NO}$ and LPO levels in the Crataegus treatment group were significantly lower than those in the I/R group. They were significantly higher in the I/R group than those in the control group.

Table 3: Oxidative stress in control, $\mathrm{I} / \mathrm{R}$ and $\mathrm{I} / \mathrm{R}+\mathrm{Crataegus,}$ rats $(n=12$, mean \pm SD)

\begin{tabular}{ccccc}
\hline Oxidative stress & control & I/R & $\begin{array}{c}\text { I/R }+ \\
\text { Crataegus }\end{array}$ & P \\
\hline $\begin{array}{c}\text { NO ( } \mu \mathrm{mol} / \mathrm{ml}) \\
\text { In Serum }\end{array}$ & $\mathbf{1 4 . 0 2 \pm 0 . 5}$ & $26.72 \pm 1.4$ & $\mathbf{1 8 . 0 7 \pm 1 . 6}$ & $\mathbf{0 . 0 0 1}$ \\
\hline $\begin{array}{c}\text { LPO (nmol/ml) } \\
\text { In Serum }\end{array}$ & $\mathbf{0 . 3 4} \pm \mathbf{0 . 0 0 3}$ & $\mathbf{1 . 0 4} \pm \mathbf{0 . 0 3}$ & $\mathbf{0 . 7 1} \pm 0.07$ & $\mathbf{0 . 0 0 1}$ \\
\hline
\end{tabular}

NO: nitric oxide , LPO: lipid peroxidation

As indicated in the histopathological evaluation, there were no pathological changes in heart tissue of the control group (Group 1). Heart specimens from rats after I/R exhibited focal necrosis and infiltration of leukocytes (Group 2). Crataegus treatment significantly decreased these pathological changes (Group 3). Histological tissue damage was milder in the Crataegus treatment group than that in the sham group.
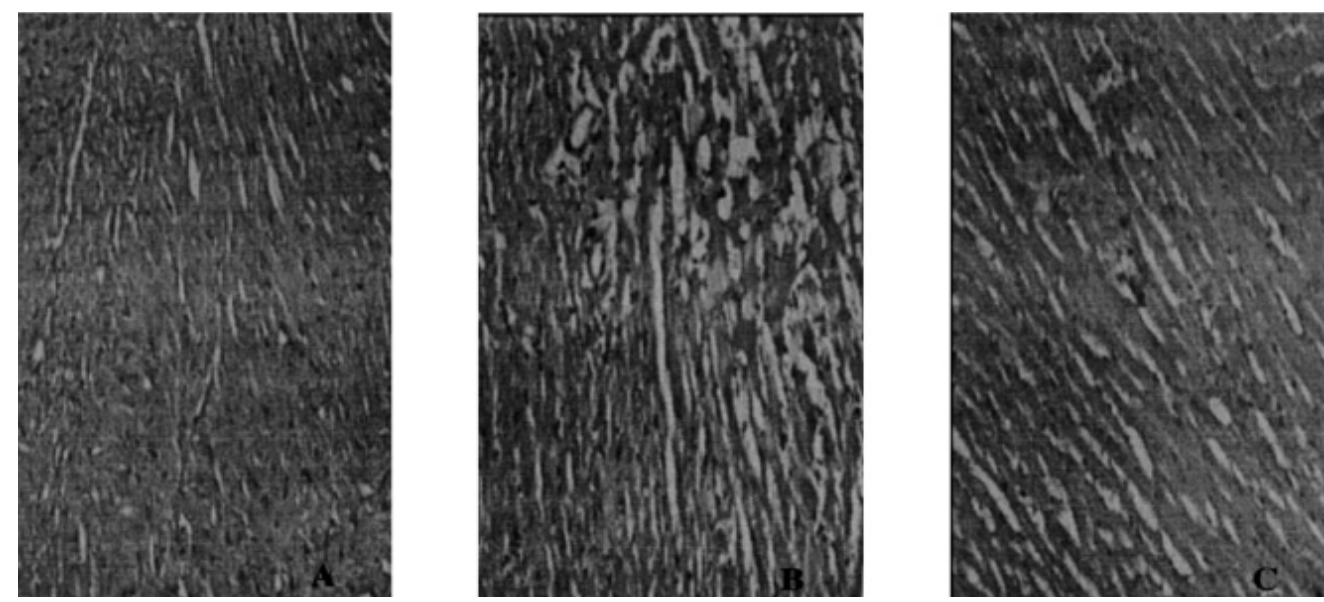

Figure 2 A: Normal heart tissue(Group 1) B: Histopathological findings 60 min after I/R(Group 2); C: Histopathological findings $60 \mathrm{~min}$ after I/R + Crataegus (Group 3). 


\section{Discussion:}

The present results show that aqueous extract of Crataegus leaves could protect myocardial ischemic damage in a rat. through, reduced oxidative stress levels induced by myocardial ischemic. Aqueous extract of Crataegus leaves contains phytochemicals including glycosides, proteins, saponins, tannins, phenolic compounds and flavonoids which are known to exhibit medicinal as well as physiological activities. Flavonoid are hydroxylated phenolic substances known to be synthesized by plants in response to microbial infection. They have been found to be anti-microbial substances against wide array of microorganisms invitro. They are also effective antioxidants. [17] The presence of these phytochemicals in aqueous extract of Crataegus leaves could be contributory to its antioxidant activity observed in this investigation. In the present experiment the order of increasing relative abundance of these phytochemical in the aqueous extract of Crataegus leaves is glycosides, proteins, saponins, tannins, phenolic compounds and flavonoids. [18] The heavy metal levels observed in the aqueous extract of Crataegus are summarized in Table 2,In the aqueous extract, Potassium recorded the highest concentration in the leaves was $171.2 \mathrm{ppm}$, Potassium is accumulated within human cells by the action of the Na, K- ATPase (sodium pump) and it is an activator of some enzymes; in particular co-enzyme for normal growth and muscle function .Potassium deficiency causes nervous disorder, diabetes, and poor muscular control resulting in paralysis. The high content of $\mathrm{K}$ in the leaves of Crataegus may be useful as a medicinal plant for the management and treatment of these disorders. [19]Sodium involves in the production of energy, transport of amino acids and glucose into the body cells. The concentration of $\mathrm{Na}$ in was $19 \mathrm{ppm}$. The concentration of Ca was $18.3 \mathrm{ppm}$.Calcium is essential for healthy bones, teeth and blood. The health of the muscles and nerves depends on calcium. It is required for the absorption of dietary vitamin B, for the synthesis of the neurotransmitter acetylcholine, for the activation of enzymes such as the pancreatic lipase. Deficiency of calcium causes rickets, osteomalacia and scurvy [20]. The concentration of Fe was $5.1 \mathrm{ppm}$ iron is essential component of haemoglobin and the cytochromes. Serves in the expression of genes for receptors of ferritin, trans ferritin and metallothioneins.[21] Zinc recorded a concentration of $3.2 \mathrm{ppm}$ cofactor in more than 100 enzymatic reactions and essential component of nuclear DNA binding proteins; serves in the expression of genes for metallothioneins. Zinc deficiency causes a block in protein and nucleic acid synthesis. The immune system, the skin and the gastro-intestinal tract are the tissues of the body with the highest rate of protein synthesis that are affected by deficiency. [22]Copper is essential cofactor in several reactions concerning iron use, collagen synthesis, and suppression of free radicals. It Serves in the expression of genes for several enzymes[23]. The concentration of $\mathrm{Cu}$ in aqueous extract of Crataegus was 2.3ppm. The concentration of $\mathrm{Mg}$ was 1.9ppm .Magnesium improves insulin sensitivity, protect against diabetes and its complications and reduce blood pressure.In the leaves of Crataegus, the concentration of $\mathrm{Cr}, \mathrm{Cd}$ was less than one. Oxidative stress has been implicated in the pathology ofmany diseases such as inflammatory conditions, cancer, diabetes and aging [24].Free radicals induced by peroxidation have gained much importance because of their involvement in several pathological conditions such as atherosclerosis, ischemia, liver disorder, neural disorder, metal toxicity and pesticide toxicity [25].Reactive oxygen species (ROS) such as superoxide anions, hydroxyl radical and nitric oxide inactivate enzymes and damage important cellular component causing injury through lipid peroxidation and covalent binding[26]. Antioxidants may offer resistance against the oxidative stress by scavenging the free radicals, inhibiting the lipid peroxidation and by other mechanism and thus prevent disease[27]. It is ubiquitously known that most antioxidants are flavonoids, like quercetin, rutin or myricetin [28]. In contrast, Crataegus leaves have been shown to possess antioxidant properties.

Crataegus can be reduced oxidative stress levels induced by myocardial ischemic. through increase coronary blood flow [29]. This may be due to relaxation of coronary arteries, which directly increases blood flow or through an increase in contraction and relaxation velocities, which increases the diastolic interval and thus allows more time for blood passage through the coronary arteries [30]. Crataegus's positive inotropic action may also be due to inhibition of oxidative stress levels of NO and LPO and myocardial $\mathrm{Na}+/ \mathrm{K}+$ ATPase which is an integral membrane enzyme that maintains cardiac resting potential [31]. It also decreases blood pressure which results in an increase in exercise tolerance during the early stage of congestive heart failure [32]. Surprisingly, Crataegus has the ability to regulate both low and high blood pressure. With the bioflavanoids reportedly dilating both peripheral and coronary blood vessels leading to its use in angina [33]; the procyanidins content is claimed to support the vasorelaxant effects [34] Crataegus's glycoside component has also been reported to increase vagal tone of the heart [35]. The principal activity, commonly proposed for its cardioactive effect is its ability to inhibit the enzyme phosphodiesterase which ultimately 
results in an increase in intracellular cyclic nucleotides and a subsequent positive inotropic effect [36]. Crataegus has also been reported to have angiotensin converting enzyme inhibiting effect [37] .It may also have a cardio-protective effect due to its activity to decrease the oxygen demands of cardiac tissue [38]. Varying results have been observed regarding the effect of Hawthorn and its constituents on heart rate. In majority of in vitro studies, an increase in heart rate has been spotted while conversely, most in vivo studies report a decrease in heart rate [39].

\section{Conclusion:}

The present study reveals that the aqueous extract of Crataegus (Hawthorn) contains glycosides, tannins, proteins, saponins, phenolic compounds flavonoids and some trace elements. Results suggest that Crataegus treatment protects the rat heart against Ischemia-reperfusion induced myocardial injuries.

\section{References:}

1. Yung L.M., leung F.P., Yao X., chen Z.Y. and Huang $Y$. Reactive oxygen species in vascular wall.cardiovasc. Hematol.Disord Drug Targets(2006) ; 6 :1-19.

2. Kang M., Kim D.H. ,Cho C., Chung H.S. and Kang C.W. et al., Anti ischemia effect of Aurantii fructus on contractile dysfunction of ischemic and reperfused rat heart .J.Ethaopharmacol (2007); 111:584-591.

3. Pereira R.P. ,Fachinetto R., Souza A., Puntel R.l. and Santos G.N. et al antioxidant effects of different extracts from Melissa officinalis, Neurochem, Res(2008); 34: 973983.

4. Schmidt U., Kuhn U., Ploch M. and Hubner W.-D. Efficacy of the hawthorn preparation LI 132 in 78 patients with chromic congestive heart failure defined as NYHA functional class ii. Phytomed.(1994); 1: 17-24.

5. Von Eiff M. Hawthorn/passion flower extract and improvement in physical capacity of patients with dyspnoea class ii of the NYHM functional classification. Acta Theriol. 20, 47-66, (1994).

6. Rogers K. L., Grice I. D. and Griffiths L. R. Inhibition of platelet aggregation and 5-ht release by extracts of australian plants used traditionally as headache treatments. Eur. J. Pharm. Sci.(2000); 9: 355-363.

7. Bahorun T., Gressier B., Trotin F., Brunet C., Dine T., Luyckx M., Vasseur J., Cazin M., Cazin J. C. and Pinkas M. Oxygen species scavenging activity of phenolic extracts from hawthorn fresh plant organs and pharmaceutical preparations. Arzneimittel-Forsch(1996); 46: 1086-1089.

8. Bahorun T., Trotin F., Pommery J., Vasseur J. and Pinkas
M. Antioxidant activities of Crataegus monogyna extracts. Planta Med.(1994); 60: 323-328.

9. Zhang Z., Chang Q., Zhu M., Huang Y., Hoa W. K. K. and Chen Z. Y. Characterization of antioxidants present in hawthorn fruits. J. Nutr. Biochem.(2001a);12: 144-152.

10. Miller A. L. Botanical influences on cardiovascular disease. J. Clin. Ther. (1998);3:422-431.

11. Mohammed, M. T., “ Study of Some Mirabilis jalapa L. Leaves Components and Effect of Their Extracts on Growth of Pathogenic bacteria" Al-Mustansirya J.Sci. (2012);23:6,117-124.

12.Zhou, H.; Hou, S.Z.; Luo, P.; Zeng, B.; Wang, R.J.; Wong, Y.F.; Jiang, Z.H.; Liu, L. Ginseng protects rodent hearts from acute myocardial ischemia-reperfusion injury through GR/ ER-activated RISK pathway in an endothelial NOS-dependent mechanism. J. Ethnopharmacol.(2011); 135:287-298.

13. Kadhim, S.M., "protective effects of nigella sativa (black seed) on ischemia-reperfusion inducedmyocardial injuries". Int. J. Chem. Sci.(2013); 11(2): 1199-1208.

14.van Bezoijen R., Que I., Ederveen A. G., Klooster- boer H. J., Papapoulos S. E. and Lowik C. W., "Plasma Nitrate and Nitrite Level are Regulated by Ovarian Steroids But do not Correlate with Trabecular Bone Mineral Density in Rats," Journal of Endocrinology, ,(1998) :Vol. 159, pp. 2734. [www.IVSL.org].

15. Thayer W., "Lipid Peroxide in Rats Treated Chronically with Adriamycin," Biochemical Pharmacology, (1984); Vol. 33; No. 14, pp. 2259-2263.

16.Barnes, J., Anderson, L.A., Phillipson, J.D.: Herbal Medicines. A guide for health care professionals. First Ed. Pharmaceutical Press Publication, London(1996); p.284287.

17. Okwu, D.E. ,Phytochemicals and vitamin content of indigenous species Southeastern Nigeria. J. Sustainable Agriculture and Environment,(2004);6(1): 30-37.

18. Olakunle S., Onyechi O., James O.,. Toxicity, anti-lipid peroxidation, invitro and invivo evaluation of antioxidant activity of Annona muricata ethanol stem bark extract; American Journal of Life Sciences,(2014); 2(5): 271-277. [www.IVSL.org].

19. Birch, N.J. \& Padgham, C.. Handbook on Metals in Clinical and Analytical Chemistry. Marcel Dekker, (1994) New York.

20. Charles, P. (1992). Calcium absorption and calcium bioavailability. J. Int. Med.; 231(2):161-65.

21. Chen, K.S., Tseng, C.L. \& Lin, T.H. Trace elements in natural drugs determined by INAA. J. Radioanal. Nucl. Chem.; (1993);170(1): 265-80.

22. World Health Organization ; Trace elements in human 
nutrition and health (book), Geneva (1996).

23.Durdana, R. H., Shahnaz, I. \& Sheikh, G.H. ,Assessment of the level of trace metals in Commonly edible vegetables locally available In the markets of karachi city. Pak. J. Bot. (2007);39(3): 747-751.

24. Marx JL. Oxygen free radicals linked to many diseases. Science, (1987) ;235, 529.

25. Pandey S, Sharma M, Chaturvedi $P$, et al. Protective effect of Rubia cordifolia on lipid peroxide formation in isolated rat liver homogenate. Indian J Exp Biol, (1994); 32, 180-3.

26. Geesin JG, Gordon JS, Berg RA. Retinoids affect collagen synthesis through inhibition of ascorbate-induced lipid peroxidation in cultured human dermal fibroblast. Arch Biochem Biophys, (1990); 278, 350-5.

27. Youdim KA, Joseph JA. A possible emerging role of phytochemical in improving age-related neurological dysfunctions- a multiplicity of effects. Free Rad Biol Med, (2001); 30, 583-94.

28. Kandaswami C, Middleton E. Free radical scavenging and anti-oxidant activity of plant flavonoids. Adv Exp Med Biol, (1994);366, 351-76.

29. Taskov, M: .On the coronary and cardiotonic action of Crataemon. : Acta Physiol. Pharm.(1977) ;3: 53-57.

30. Schussler, M., Holz, J., Fricke, U.: Myocardial effects of flavanoids from Crataegeus species. Arzneim.Forsch. Drug Res.(1995); 45:842-45.

31. Holzl, J. et al.: Studies of pharmacological mechanism of Crataegus fraction and their analytical characteristics. Arch. Pharm.(1988); 321; 631.

32. Leuchtgens, H.: Crataegus special extract WS 1442 in NYHA II heart failure. A placebo controlled randomized double blind study. Fortschr Med.(1993); 111: 352-54.

33. Wagner, H. and Grevel, J.: Cardioactive Drugs IV. Cardiotonic amines from Crategeus oxycantha. Planta Medica (1982);45: 99-101.

34. Rewerski, W. et al.: Some pharmacological properties of flavan polymers isolated from hawthorn. Arzneim Forsch Drug Res.(1967); 17:490-91,(1967).

35.Petkov, E., Nikolov, N., Vzunov, P.: Inhibitory effect of some flavanoids and flavanoid mixtures on cyclic AMP phosphodiesterase activity of Rat heart. Planta Medica. (1981) ;43; 183-86.

36.Reutxer, H.D.: Crategeus as cardiac plant. J. Phytother,(1994) ;15:73-81.

37. Lacaille-Dubois, V., Franck, U., Wagner, H. : Search for potential angiotensin converting enzyme (ACE)inhibitors from plants. Phytomedicine.(2001);8, 47-52. [www.IVSL. org].

38. Nasa, Y., Hashizume A.N., Hoque, E., Abiko, Y.: Protective effect of Crataegus extract on the cardiac mechanical dysfunction in isolated perfused working rat heart. Arzneim Forsch Drug Res.(1993); 43:945-49.

39. Ammon, H. and Kaul, R.: Heat circulation mechanism of action of Crataegus extract, flavanoid and procyanidin. Part I. History and workings. Dtsch. Apoth. Ztg.(1994); 134:433436. 